\title{
TAVI risk scoring using established versus new scoring systems: role of the new STS/ACC model
}

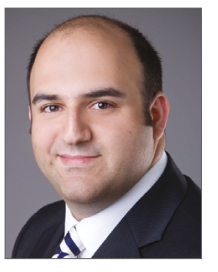

Mani Arsalan ${ }^{1 *}, \mathrm{MD}$; Maren Weferling ${ }^{2}$, MD; Florian Hecker' ${ }^{1}, \mathrm{MD}$; Giovanni Filardo 3 , PhD, MPH; Won-Keun Kim ${ }^{1,2}$, MD; Benjamin D. Pollock ${ }^{3}$, MSPH, CPH; Arnaud Van Linden ${ }^{1}, \mathrm{MD}$; Annika Arsalan-Werner ${ }^{1}, \mathrm{MD}$; Mathias Renker², MD; Mirko Doss ${ }^{1}, \mathrm{MD}$, PhD; Simon Kalbas²; Christian W. Hamm²,4, MD, PhD; Christoph Liebetrau ${ }^{2}, \mathrm{MD}$, PhD; Michael J. Mack ${ }^{5}$, MD; Thomas Walther ${ }^{1}, \mathrm{MD}, \mathrm{PhD}$

1. Department of Cardiac Surgery, Kerckhoff Heart Center, Bad Nauheim, Germany; 2. Department of Cardiology, Kerckhoff Heart Center, Bad Nauheim, Germany; 3. Department of Epidemiology, Baylor Scott and White Health, Dallas, TX, USA; 4. Department of Cardiology, Justus Liebig University of Giessen, Giessen, Germany; 5. The Heart Hospital Baylor Plano, Plano, TX, USA

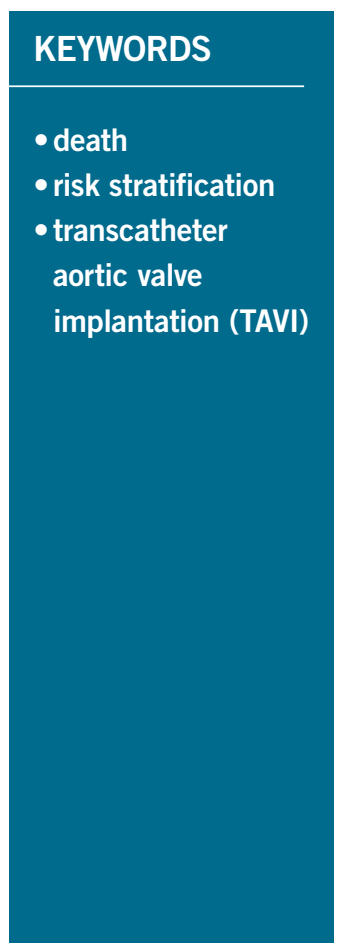

\begin{abstract}
Aims: The aim of this study was to validate the recently developed STS/ACC TAVR in-hospital mortality risk score for predicting in-hospital mortality after transcatheter aotic valve implantation (TAVI) and to compare its ability to predict 30-day mortality with that of four other established risk models (EuroSCORE I, EuroSCORE II, STS-PROM, and German AV Score).

Methods and results: The study cohort included 946 consecutive patients who underwent TAVI between 2013 and 2015. Each of the five scores was fitted as a continuous linear variable into a logistic regression model estimating 30-day mortality. The STS/ACC TAVR score was additionally analysed for in-hospital mortality. C-statistics and likelihood ratio (LR) test p-values were estimated for each model to describe the model fit. The ability of the STS/ACC score to predict in-hospital mortality was similar to the reported STS/ACC TVT registry data (this study's C-statistic 0.65 vs. STS/ACC TVT registry 0.66 ). The STSPROM score (C-statistic $=0.68$; LR $p<0.0001)$ and the new STS/ACC TAVR score (C-statistic $=0.68$; LR $\mathrm{p}<0.0001$ ) were superior to the other scores (EuroSCORE I [C-statistic $=0.55 ; \mathrm{LR} p=0.02]$, EuroSCORE II [C-statistic $=0.58$; LR $p=0.02]$, German AV Score [C-statistic $=0.62$; LR $p<0.01]$ ) for prediction of 30-day mortality.
\end{abstract}

Conclusions: These data show the superiority of the STS-PROM and STS/ACC TAVR scores compared with other existing risk calculation models in predicting 30-day mortality after TAVI in a German all-comers population. The STS/ACC TAVR score, however, is easier to calculate (12 vs. 28 variables), and may thus gain wider acceptance and be accompanied by improved inter-observer reliability. 


\section{Abbreviations}

$\begin{array}{ll}\text { ES I } & \text { EuroSCORE I } \\ \text { ES II } & \text { EuroSCORE II } \\ \text { GARY } & \text { German Aortic Valve Registry } \\ \text { German AV Score } & \text { German Aortic Valve Score } \\ \text { LR } & \text { likelihood ratio } \\ \text { SAVR } & \text { surgical aortic valve replacement }\end{array}$

STS/ACC TAVR Society of Thoracic Surgeons/American College of Cardiology TAVR in-hospital mortality risk score

\section{STS/ACC TVT}

Society of Thoracic Surgeons/American College of Cardiology Transcatheter Valve Therapy

STS-PROM

TAVI Society of Thoracic Surgeons Predicted Risk of Operative Mortality

transcatheter aortic valve implantation

\section{Introduction}

Transcatheter aortic valve implantation (TAVI) is being used increasingly worldwide, especially since outcomes comparable to those of conventional surgery have been demonstrated for highrisk patients ${ }^{1}$. In addition, the indication for using TAVI has been gradually extended to lower-risk patients ${ }^{2,3}$. Although accurate risk prediction is essential for patient-centric care and informed consent, a reliable risk score model estimating the TAVI procedural success is not yet available, despite more than ten years of clinical experience with TAVI. In order to design a TAVI-specific risk score based on a larger cohort, the Society of Thoracic Surgeons/ American College of Cardiology (STS/ACC) Transcatheter Valve Therapy (TVT) Registry TAVI in-hospital mortality risk score (STS/ACC TAVR score) was recently published ${ }^{4}$. It is based on the STS/ACC TVT Registry that captures all commercial TAVI procedures performed in the USA ${ }^{4}$.

Although a validation cohort was used for internal validation, this risk score has not been externally validated. The present study was designed to evaluate the ability of this new model to predict in-hospital and 30-day mortality in an all-comers German TAVI cohort and to compare it with previously established risk scores in terms of the ability to predict 30-day mortality.

\section{Editorial, see page 1503}

\section{Methods}

The study cohort included 946 consecutive patients who underwent TAVI between January 2013 and December 2015 at our centre. Data from our institutional database for these patients were used to calculate procedural risk scores, including EuroSCORE I (ES I) ${ }^{5}$, EuroSCORE II (ES II) ${ }^{6}$, Society of Thoracic Surgeons Predicted Risk of Operative Mortality (STS-PROM) ${ }^{7}$, German Aortic Valve Score (German AV Score) ${ }^{8}$, and the newly developed STS/ACC TAVR score (Table 1) ${ }^{4}$. In-hospital and 30-day mortality was available for all patients. Each of the five procedural scores was fitted as a continuous linear variable into a logistic regression model estimating 30-day mortality. The analysis was repeated by modelling each score using restricted cubic splines with three knots $^{9,10}$. The C-statistic, Somer's D, Brier score, and likelihood ratio (LR) test p-values were estimated for each of the ten 30-day models to describe the model discrimination and calibration. Receiver operating characteristic (ROC) curves were generated for each score, and differences between the scores' C-statistics and 95\% confidence intervals were calculated, with p-values being adjusted for the multiple testing false discovery rate. To assess calibration visually, plots of observed versus predicted mortality were generated for each model, with HosmerLemeshow goodness-of-fit p-values estimated for all models. The STS/ACC in-hospital mortality score was additionally analysed for in-hospital mortality. All analyses were conducted using SAS Version 9.3 (SAS Institute Inc., Cary, NC, USA). The study was approved by the Institutional Review Board at our centre.

\section{Results}

A total of 946 patients (median age 82.1 [interquartile range 78.285.8] years; $51.5 \%$ female) underwent TAVI during the study period. Common comorbidities were chronic obstructive pulmonary disease $(20.4 \%)$, prior stroke $(14.6 \%)$, coronary artery disease $(64 \%)$ and prior cardiac surgery $(21.7 \%)$. Baseline characteristics are listed in Table 2. The rate of transapical TAVI was high $(37.2 \%)$ and decreased over the study period. Risk scores and in-hospital and 30-day mortality data were available for all patients. As indicated by the risk scores (median ES I 21.1, ES II 5.0, STS-PROM 5.0) and comorbidities, most patients were at high or intermediate risk, which is representative of the current clinical practice in Germany ${ }^{11}$. During the hospital stay, 46 patients (4.9\%) died; mortality at 30 days was $6.3 \%$ (60/946).

The C-statistic for the STS/ACC TAVR score for the prediction of in-hospital mortality in our cohort was 0.65 (Figure 1). The C-statistics for the STS/ACC TAVR (0.68) and STS-PROM (0.68) scores for prediction of 30-day mortality indicate superiority to the other scores (ES I [0.55], ES II [0.58] and German AV Score [0.62]; using either model - continuous variables or cubic splines) (Table 3, Figure 2). In comparing the C-statistics, 30-day mortality was predicted significantly better by the STS/ACC TAVR score than by ES I ( $p=0.023)$ or ES II ( $p=0.055)$. The STS-PROM score was also superior to ES I $(p=0.023)$ and ES II $(p<0.01)$. The calibration plots of observed versus predicted mortality (Figure 3 ), Somer's D, and Brier score (Table 3, Figure 3) confirmed these results.

\section{Discussion}

This is the first study to evaluate the STS/ACC TAVR in-hospital mortality score in a non-US population undergoing TAVI and to investigate its ability to predict 30-day mortality compared with other, established, risk models. The similarity between C-statistics for in-hospital mortality in our cohort compared with the validation cohort in the original report ( 0.65 vs. 0.66 ) shows that the risk model is able to predict in-hospital mortality in a patient cohort outside of the population in which it was developed; thus, our study provides external validation of the new score. In our German cohort, there was similar precision to the STS/TVT Registry patients ${ }^{4}$. 
Table 1. Risk factors used for calculation of each risk score.

\begin{tabular}{|c|c|c|c|c|c|}
\hline Criterion/risk factor & ES I & ES II & German AV Score & STS & STS/ACC \\
\hline Age & $x$ & $x$ & $x$ & $x$ & $\mathrm{x}$ \\
\hline Sex & $x$ & $x$ & $x$ & $x$ & $x$ \\
\hline Body physique (height/weight) & & & $x$ & $x$ & \\
\hline Race & & & & $x$ & $x$ \\
\hline LV function & Good, moderate, poor & Good, moderate, poor, very poor EF & Good, moderate, poor & $\mathrm{EF}$ & \\
\hline Cardiac symptoms & Unstable angina & CCS Class IV angina & & $\begin{array}{l}\text { At time of admission } \\
\text { and surgery }\end{array}$ & \\
\hline Myocardial infarction & Within 90 days & Within 90 days & Within last 3 weeks & Prior MI & \\
\hline NYHA & & All & NYHA Class IV & All & NYHA Class IV \\
\hline Rhythm & & & No sinus rhythm & Arrhythmia & \\
\hline Hypertension & & & & $x$ & \\
\hline Endocarditis & $x$ & $x$ & $x$ & $x$ & \\
\hline Coronary artery disease & & & & $x$ & \\
\hline Previous cardiac surgery & $x$ & $x$ & $x$ & $x$ & \\
\hline Tricuspid valve disease & & & & $x$ & \\
\hline Mitral valve disease & & & & $x$ & \\
\hline Chronic lung disease & $\begin{array}{l}\text { Long-term use of } \\
\text { bronchodilators or steroids } \\
\text { for lung disease }\end{array}$ & $\begin{array}{l}\text { Long-term use of bronchodilators } \\
\text { or steroids for lung disease }\end{array}$ & & $x$ & Severe \\
\hline Pulmonary hypertension & $x$ & Moderate, severe & $x$ & & \\
\hline COPD & & & $x$ & & \\
\hline Cerebrovascular disease & $\begin{array}{l}\text { Affecting ambulation or } \\
\text { day-to-day functioning }\end{array}$ & & & $\mathrm{x}$ & \\
\hline Peripheral artery disease & $\mathrm{x}$ & $\mathrm{x}$ & $\mathrm{x}$ & $x$ & \\
\hline Renal function & $\begin{array}{l}\text { Preoperative creatinine } \\
\quad>200 \mu \mathrm{mol} / \mathrm{L}\end{array}$ & $\begin{array}{l}\text { Preoperative creatinine } \\
\quad>200 \mu \mathrm{mol} / \mathrm{L}\end{array}$ & $\begin{array}{c}\text { Preoperative dialysis or } \\
\text { preoperative renal } \\
\text { failure }\end{array}$ & $\begin{array}{c}\text { Dialysis or creatinine } \\
\text { level }\end{array}$ & $\begin{array}{l}\text { Dialysis or glomerular } \\
\text { filtration rate }\end{array}$ \\
\hline Diabetes & & $x$ & & $x$ & \\
\hline Mobility & & Poor & & & \\
\hline Immunocompromise & & & & $x$ & \\
\hline \multirow[t]{6}{*}{ Status } & Emergency & Urgency & Emergency & Urgency & Urgency \\
\hline & Critical preoperative state & Critical preoperative state & $\begin{array}{l}\text { Critical preoperative } \\
\text { state }\end{array}$ & Cardiogenic shock & Cardiogenic shock \\
\hline & & & & Resuscitation & Cardiac arrest \\
\hline & & & & $\begin{array}{l}\text { Heart failure within } \\
2 \text { weeks }\end{array}$ & \\
\hline & & & & IABP & $\begin{array}{l}\text { Mechanical assist } \\
\text { device }\end{array}$ \\
\hline & & & & Inotropes & Inotropes \\
\hline Incidence & & & & First CV surgery or redo & \\
\hline Access & & & & & Non-femoral approach \\
\hline Number of criteria & 14 & 16 & 15 & 28 & 12 \\
\hline
\end{tabular}

As TAVI was initially developed for inoperable and high-risk patients, risk assessment has always been of particular importance and is recommended by the guidelines. The developers of the STS/ACC TAVR score opted for an in-hospital model, as complete data were easier to capture for this outcome than 30-day mortality. Data were thus available for almost all patients in the registry (only 1.2\% missing data for in-hospital mortality in the registry) ${ }^{4}$. Thirty-day mortality, however, is the standard criterion that is routinely assessed for preoperative evaluation and recommended by the guidelines. We demonstrate that the STS/ACC TAVR score can be used for prediction of 30-day outcome and performs better than other scores for this purpose (ES I and II and German AV Score).

The standard models for risk stratification in cardiac patients are currently the STS-PROM in the USA and the ES I and ES II in Europe $^{12,13}$. All of these models, however, were designed for conventional cardiac surgery and are based on a patient population that is different from the typical cohort of elderly TAVI patients with comorbidities. Consequently, several studies have shown the 
Table 2. Baseline characteristics.

\begin{tabular}{|c|c|}
\hline Characteristic & Median [IQR] or n (\%) \\
\hline Age, years & $82.1[78.2-85.8]$ \\
\hline Female gender, $\mathrm{n}(\%)$ & $487(51.5 \%)$ \\
\hline EuroSCORE I, \% & $21.1[15.0-29.5]$ \\
\hline EuroSCORE II, \% & $5.0[3.0-8.3]$ \\
\hline STS score, \% & $5.0[3.4-7.6]$ \\
\hline German AV Score, \% & $3.7[2.3-6.0]$ \\
\hline STS/ACC in-hospital mortality score, \% & $4.2[2.9-6.3]$ \\
\hline NYHA Class III+IV & $861(91.0 \%)$ \\
\hline Transfemoral access & $594(62.8 \%)$ \\
\hline Body mass index, $\mathrm{kg} / \mathrm{m}^{2}$ & 26.9 [24.9-30.5] \\
\hline $\mathrm{GFR}, \mathrm{mL} / \mathrm{min}$ & $62.0[44.0-80.5]$ \\
\hline Hypertension & $912(96.4 \%)$ \\
\hline Diabetes & 307 (32.5\%) \\
\hline Hyperlipidaemia & 349 (36.9\%) \\
\hline COPD & $193(20.4 \%)$ \\
\hline CAD & $605(64.0 \%)$ \\
\hline Prior cardiac surgery & $205(21.7 \%)$ \\
\hline Prior CABG & $178(18.8 \%)$ \\
\hline Prior stroke & $138(14.6 \%)$ \\
\hline Sinus rhythm & $617(62.2 \%)$ \\
\hline LVEF (\%) & $60.0[50.0-65.0]$ \\
\hline Pmean (mmHg) & 42.0 [31.3-53.0] \\
\hline Aortic valve area $\left(\mathrm{mm}^{2}\right)$ & $0.7[0.5-0.8]$ \\
\hline \multicolumn{2}{|c|}{$\begin{array}{l}\text { CABG: coronary artery bypass grafting; CAD: coronary artery disease; } \\
\text { COPD: chronic obstructive pulmonary disease; GFR: glomerular filtration } \\
\text { rate; IQR: interquartile range; LVEF: left ventricular ejection fraction; } \\
\text { NYHA: New York Heart Association; Pmean: mean aortic valve gradient }\end{array}$} \\
\hline
\end{tabular}

inability of these models to assess procedural risk properly ${ }^{14-17}$. Some groups demonstrated superiority of STS-PROM over ES I and II ${ }^{14,18}$, whereas others favoured ES $\mathrm{II}^{19,20}$. The present analysis confirms that STS-PROM outperforms ES I and II and is on a par with the new STS/ACC in-hospital mortality score for TAVI patients.

In an effort to achieve more accurate risk assessment, various TAVI- or aortic valve-specific risk scores have been developed over the last few years ${ }^{8,21-23}$. Different strategies were used for this purpose. Some groups developed and evaluated their model based on multicentre data sets. For example, Seiffert and colleagues developed their model based on data from two hospitals and evaluated

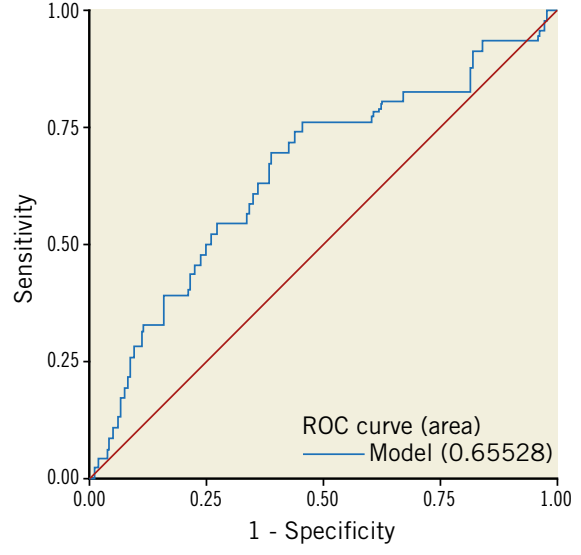

Figure 1. Ability of the STS/ACC score to predict in-hospital mortality. Receiver operating characteristic (ROC) plot showing the prognostic values of the STS/ACC TAVR score for the prediction of in-hospital mortality. STS/ACC TAVR score: Society of Thoracic Surgeons/American College of Cardiology TAVR in-hospital mortality risk score

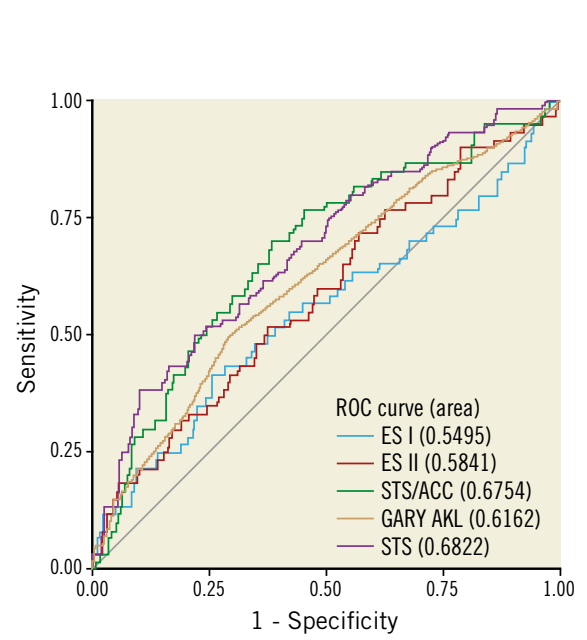

Figure 2. Ability of five different risk scores to predict 30-day mortality. Receiver operating characteristic (ROC) plots showing the prognostic values of the STS/ACC TAVR score, STS-PROM, ES I, ES II and German AV Score for the prediction of 30-day mortality. ES I: EuroSCORE I; ES II: EuroSCORE II; German AV Score: German Aortic Valve Score; STS/ACC TAVR score: Society of Thoracic Surgeons/American College of Cardiology TAVR in-hospital mortality risk score; STS-PROM: Society of Thoracic Surgeons Predicted Risk of Operative Mortality

Table 3. Model statistics for prediction of 30-day mortality after TAVI.

\begin{tabular}{|l|c|c|c|c|c|c|c|c|c|c|}
\hline \multicolumn{1}{|c|}{ Statistic } & ES I & $\begin{array}{c}\text { ES I } \\
\text { spliney }\end{array}$ & ES II & $\begin{array}{c}\text { ES II } \\
\text { spline }\end{array}$ & STS/ACC & $\begin{array}{c}\text { STS/ACC } \\
\text { spline }\end{array}$ & $\begin{array}{c}\text { German } \\
\text { AV Score }\end{array}$ & $\begin{array}{c}\text { German AV } \\
\text { Score spline }\end{array}$ & $\begin{array}{c}\text { STS } \\
\text { STS } \\
\text { spline }\end{array}$ \\
\hline C-statistic & 0.55 & 0.59 & 0.58 & 0.58 & 0.68 & 0.68 & 0.62 & 0.62 & 0.68 & 0.68 \\
\hline LR p-value & $p=0.03$ & $p=0.02$ & $p=0.01$ & $p=0.02$ & $p<0.001$ & $p<0.0001$ & $p<0.01$ & $p<0.01$ & $p<0.0001$ & $p<0.0001$ \\
\hline $\begin{array}{l}\text { Hosmer- } \\
\text { Lemeshow } p \text {-value }\end{array}$ & 0.24 & 0.89 & 0.77 & 0.86 & 0.47 & 0.26 & 0.65 & 0.80 & 0.75 & 0.72 \\
\hline Brier score & 0.0591 & 0.0591 & 0.0589 & 0.0589 & 0.0590 & 0.0590 & 0.0588 & 0.0588 & 0.0577 & 0.0577 \\
\hline \multicolumn{2}{|c|}{0.1823} & 0.1682 & 0.1682 & 0.3507 & 0.3599 & 0.2325 & 0.2325 & 0.3644 & 0.3644 \\
\hline
\end{tabular}



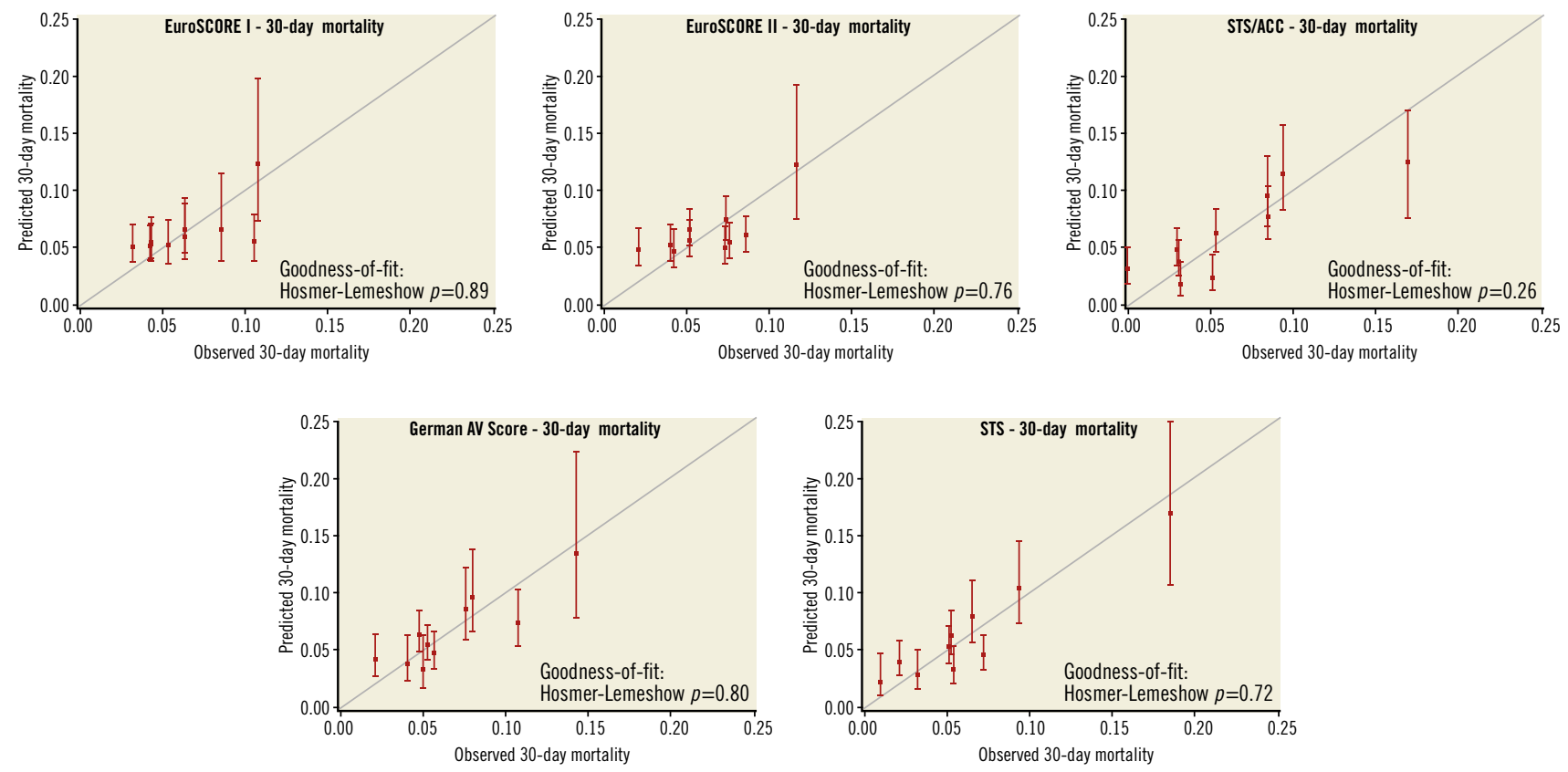

Figure 3. Calibration plots for splined risk models. Calibration plots showing deciles of observed 30-day mortality versus predicted 30-day mortality for the STS/ACC TAVR score, STS-PROM, ES I, ES II and German AV Score. ES I: EuroSCORE I; ES II: EuroSCORE II; German AV Score: German Aortic Valve Score; STS/ACC TAVR score: Society of Thoracic Surgeons/American College of Cardiology TAVR in-hospital mortality risk score; STS-PROM: Society of Thoracic Surgeons Predicted Risk of Operative Mortality

the score on patients who underwent TAVI at a third centre ${ }^{23}$ However, due to a small event rate after 30 days and a small patient cohort, their study was not powered to develop a risk model for 30-day mortality; therefore, their one-year mortality risk score had a low C-statistic of 0.6. Similarly, the TAVI2-SCORe was developed to predict one-year mortality based on 511 patients who underwent TAVI at two centres in the Netherlands and Italy ${ }^{21}$. The authors claimed that in their analysis the TAVI2-SCORe outperformed STS, ES I, and ES II; however, the performance of the score was evaluated on the same patient cohort that was used for model development. This might invalidate the results.

As it is necessary to use larger cohorts to develop reliable models for 30-day mortality, registry data are used to design a specific risk score. The FRANCE-2 risk score is a 21-point predictive score based on the French Aortic National CoreValve and Edwards (FRANCE 2) registry ${ }^{24}$. The development cohort consisted of 2,552 patients and the validation cohort 1,281 patients. The C-statistic of the development cohort was 0.67 ; however, it proved to be only 0.59 in the validation cohort and thus this risk score was not superior to the established models.

The German AV Score, which was published in 2013, uses national registry data and includes both TAVI $(n=573)$ and surgical aortic valve replacement (SAVR) $(n=10,574)$ patients $^{8}$. Thus, it uses a more disease-specific (rather than procedure-specific) approach. By including SAVR patients, the model was designed to help inform decision making regarding SAVR and TAVI. As with the STS/ACC TAVR and FRANCE-2 scores, it is based on a large registry and captures all TAVI procedures performed nationwide. In contrast to the US STS/ACC TVT Registry, the German Aortic Valve Registry (GARY) is not limited to commercial TAVI procedures ${ }^{25,26}$. Kötting and colleagues reported a C-statistic of 0.808 , which is, to our knowledge, the highest value reported for a TAVI score; however, the score was evaluated on the same cohort that was used for risk development and only $5 \%$ of the patients underwent $\mathrm{TAVI}^{8}$. Thus, none of the recently developed TAVI risk score models, including TAVI2-SCORe, FRANCE-2, and the German AV Score, has proved to be superior to previously established models.

\section{Limitations}

Our study has a few limitations. Although we included almost 1,000 patients in this study, larger and more geographically diverse patient cohorts are needed to confirm our findings. This is especially important as each of the risk scores considered here was developed based on different patient populations. Another principal limitation of this analysis is the retrospective validation of the STS/ ACC model. However, the data were collected prospectively. This method allows prompt validation of the risk score model after its development. Comparing the new risk model to other TAVI-specific scores, such as the OBSERVANT or FRANCE-2 score, would help to determine the clinical significance of the new model compared to existing ones. However, the currently available data in our database do not allow us to calculate these scores. Thus, we focused on the most commonly used risk models which are recommended by the current guidelines. In addition, we report the ability of the STS/ ACC TAVR in-hospital mortality risk score to be reasonably accurate in predicting 30-day mortality although it was only designed 
for in-hospital mortality. Our assessment, however, showed the score to be superior to several commonly used 30-day risk models.

\section{Conclusions}

Here we demonstrate that, although the STS/ACC in-hospital mortality score was developed based on a US population and was designed for in-hospital mortality prediction, it is superior to the German AV Score and ES I and II in predicting 30-day mortality after TAVI. Although it requires significantly fewer variables (12 vs. 28) for risk assessment and can thus be applied more easily and quickly, we found it to be on a par with the STS-PROM score. Although all of these data support the STS-PROM and STS/ ACC TVT TAVR in-hospital mortality scores for risk estimation, it is important to keep in mind that none of the models' C-statistics exceeds 0.7 , the cut-off generally considered as satisfactory for risk prediction ${ }^{27}$. The developers of the STS/ACC in-hospital mortality score are currently working on a 30-day mortality score based on the STS/ACC TVT Registry data. Until then, both the STS-PROM and STS/ACC TAVR in-hospital score seem to be the best tools for risk prediction in TAVI patients.

\section{Impact on daily practice}

Despite more than ten years of clinical experience with transcatheter aortic valve implantation (TAVI), a reliable risk score model is not yet available. In this study, we showed that the STS-PROM and STS/ACC in-hospital mortality score are superior to the ES I, ES II and German AV Score. After validation in larger and more geographically diverse patient cohorts, the STS/ACC TAVR score may gain wider acceptance.

\section{Acknowledgements}

We thank Elizabeth Martinson, PhD, of the KHFI Editorial Office for her editorial assistance.

\section{Conflict of interest statement}

The authors have no conflicts of interest to declare.

\section{References}

1. Mack MJ, Leon MB, Smith CR, Miller DC, Moses JW, Tuzcu EM, Webb JG, Douglas PS, Anderson WN, Blackstone EH, Kodali SK, Makkar RR, Fontana GP, Kapadia S, Bavaria J, Hahn RT, Thourani VH, Babaliaros V, Pichard A, Herrmann HC, Brown DL, Williams M, Davidson MJ, Svensson LG; PARTNER 1 trial investigators. 5-year outcomes of transcatheter aortic valve replacement or surgical aortic valve replacement for high surgical risk patients with aortic stenosis (PARTNER 1): a randomised controlled trial. Lancet. 2015;385:2477-84.

2. Leon MB, Smith CR, Mack MJ, Makkar RR, Svensson LG, Kodali SK, Thourani VH, Tuzcu EM, Miller DC, Herrmann HC, Doshi D, Cohen DJ, Pichard AD, Kapadia S, Dewey T, Babaliaros V, Szeto WY, Williams MR, Kereiakes D, Zajarias A, Greason KL, Whisenant BK, Hodson RW, Moses JW, Trento A, Brown DL,
Fearon WF, Pibarot P, Hahn RT, Jaber WA, Anderson WN, Alu MC, Webb JG; PARTNER 2 Investigators. Transcatheter or Surgical Aortic-Valve Replacement in Intermediate-Risk Patients. $N$ Engl J Med. 2016;374:1609-20.

3. Thourani VH, Kodali S, Makkar RR, Herrmann HC, Williams M, Babaliaros V, Smalling R, Lim S, Malaisrie SC, Kapadia S, Szeto WY, Greason KL, Kereiakes D, Ailawadi G, Whisenant BK, Devireddy C, Leipsic J, Hahn RT, Pibarot P, Weissman NJ, Jaber WA, Cohen DJ, Suri R, Tuzcu EM, Svensson LG, Webb JG, Moses JW, Mack MJ, Miller DC, Smith CR, Alu MC, Parvataneni R, D’Agostino RB Jr, Leon MB. Transcatheter aortic valve replacement versus surgical valve replacement in intermediate-risk patients: a propensity score analysis. Lancet. 2016;387:2218-25.

4. Edwards FH, Cohen DJ, O'Brien SM, Peterson ED, Mack MJ, Shahian DM, Grover FL, Tuzcu EM, Thourani VH, Carroll J, Brennan JM, Brindis RG, Rumsfeld J, Holmes DR Jr; Steering Committee of the Society of Thoracic Surgeons/American College of Cardiology Transcatheter Valve Therapy Registry. Development and Validation of a Risk Prediction Model for In-Hospital Mortality After Transcatheter Aortic Valve Replacement. JAMA Cardiol. 2016;1:46-52.

5. Roques F, Michel P, Goldstone AR, Nashef SA. The logistic EuroSCORE. Eur Heart J. 2003;24:881-2.

6. Nashef SA, Roques F, Sharples LD, Nilsson J, Smith C, Goldstone AR, Lockowandt U. EuroSCORE II. Eur J Cardiothorac Surg. 2012;41:734-44.

7. O'Brien SM, Shahian DM, Filardo G, Ferraris VA, Haan CK, Rich JB, Normand SL, DeLong ER, Shewan CM, Dokholyan RS, Peterson ED, Edwards FH, Anderson RP; Society of Thoracic Surgeons Quality Measurement Task Force. The Society of Thoracic Surgeons 2008 cardiac surgery risk models: part 2--isolated valve surgery. Ann Thorac Surg. 2009;88:S23-42.

8. Kötting J, Schiller W, Beckmann A, Schäfer E, Dobler K, Hamm C, Veit C, Welz A. German Aortic Valve Score: a new scoring system for prediction of mortality related to aortic valve procedures in adults. Eur J Cardiothorac Surg. 2013;43: 971-7.

9. Filardo G, Hamilton C, Hamman B, Ng HK, Grayburn P. Categorizing BMI may lead to biased results in studies investigating in-hospital mortality after isolated CABG. J Clin Epidemiol. 2007;60:1132-9.

10. Harrell FE Jr. Regression Modeling Strategies - With Application to Linear Models, Logistic Regression, and Survival Analysis. New York: Springer-Verlag; 2001.

11. Walther T, Hamm CW, Schuler G, Berkowitsch A, Kotting J, Mangner N, Mudra H, Beckmann A, Cremer J, Welz A, Lange R, Kuck KH, Mohr FW, Möllmann H; GARY Executive Board. Perioperative Results and Complications in 15,964 Transcatheter Aortic Valve Replacements: Prospective Data From the GARY Registry. J Am Coll Cardiol. 2015;65:2173-80.

12. Vahanian A, Alfieri O, Andreotti F, Antunes MJ, BaronEsquivias G, Baumgartner H, Borger MA, Carrel TP, De Bonis M, 
Evangelista A, Falk V, Lung B, Lancellotti P, Pierard L, Price S, Schafers HJ, Schuler G, Stepinska J, Swedberg K, Takkenberg J, Von Oppell UO, Windecker S, Zamorano JL, Zembala M; ESC Committee for Practice Guidelines (CPG); Joint Task Force on the Management of Valvular Heart Disease of the European Society of Cardiology (ESC); European Association for Cardio-Thoracic Surgery (EACTS). Guidelines on the management of valvular heart disease (version 2012): the Joint Task Force on the Management of Valvular Heart Disease of the European Society of Cardiology (ESC) and the European Association for Cardio-Thoracic Surgery (EACTS). Eur J Cardiothorac Surg. 2012;42:S1-44.

13. Nishimura RA, Otto CM, Bonow RO, Carabello BA, Erwin JP 3rd, Guyton RA, O'Gara PT, Ruiz CE, Skubas NJ, Sorajja P, Sundt TM 3rd, Thomas JD; ACC/AHA Task Force Members. 2014 AHA/ACC Guideline for the Management of Patients With Valvular Heart Disease: a report of the American College of Cardiology/ American Heart Association Task Force on Practice Guidelines. Circulation. 2014;129:e521-643.

14. Beohar N, Whisenant B, Kirtane AJ, Leon MB, Tuzcu EM, Makkar R, Svensson LG, Miller DC, Smith CR, Pichard AD, Herrmann HC, Thourani VH, Szeto WY, Lim S, Fischbein M, Fearon WF, O'Neill W, Xu K, Dewey T, Mack M. The relative performance characteristics of the logistic European System for Cardiac Operative Risk Evaluation score and the Society of Thoracic Surgeons score in the Placement of Aortic Transcatheter Valves Trial. J Thorac Cardiovasc Surg. 2014;148:2830-7.

15. Arangalage D, Cimadevilla C, Alkhoder S, Chiampan A, Himbert D, Brochet E, Iung B, Nataf P, Depoix JP, Vahanian A, Messika-Zeitoun D. Agreement between the new EuroSCORE II, the logistic EuroSCORE and the Society of Thoracic Surgeons score: implications for transcatheter aortic valve implantation. Arch Cardiovasc Dis. 2014;107:353-60.

16. Cockburn J, Dooley M, de Belder A, Trivedi U, HildickSmith D. A comparison between surgical risk scores for predicting outcome in patients undergoing transcatheter aortic valve implantation. J Cardiovasc Surg (Torino). 2017;58:467-72.

17. Silaschi M, Conradi L, Seiffert M, Schnabel R, Schön G, Blankenberg S, Reichenspurner H, Diemert P, Treede H. Predicting Risk in Transcatheter Aortic Valve Implantation: Comparative Analysis of EuroSCORE II and Established Risk Stratification Tools. Thorac Cardiovasc Surg. 2015;63:472-8.

18. Ben-Dor I, Gaglia MA Jr, Barbash IM, Maluenda G, Hauville C, Gonzalez MA, Sardi G, Laynez-Carnicero A, Torguson R, Okubagzi P, Xue Z, Goldstein SA, Suddath WO, Kent KM, Lindsay J, Satler LF, Pichard AD, Waksman R. Comparison between Society of Thoracic Surgeons score and logistic EuroSCORE for predicting mortality in patients referred for transcatheter aortic valve implantation. Cardiovasc Revasc Med. 2011;12:345-9.

19. Barili F, Pacini D, Capo A, Ardemagni E, Pellicciari G, Zanobini M, Grossi C, Shahin KM, Alamanni F, Di Bartolomeo R,
Parolari A. Reliability of new scores in predicting perioperative mortality after isolated aortic valve surgery: a comparison with the society of thoracic surgeons score and logistic EuroSCORE. Ann Thorac Surg. 2013;95:1539-44.

20. Stähli BE, Tasnady H, Lüscher TF, Gebhard C, Mikulicic F, Erhart L, Bühler I, Landmesser U, Altwegg L, Wischnewsky MB, Grünenfelder J, Falk V, Corti R, Maier W. Early and late mortality in patients undergoing transcatheter aortic valve implantation: comparison of the novel EuroSCORE II with established risk scores. Cardiology. 2013;126:15-23.

21. Debonnaire P, Fusini L, Wolterbeek R, Kamperidis V, van Rosendael P, van der Kley F, Katsanos S, Joyce E, Tamborini G, Muratori M, Gripari P, Bax JJ, Marsan NA, Pepi M, Delgado V. Value of the "TAVI2-SCORe" versus surgical risk scores for prediction of one year mortality in 511 patients who underwent transcatheter aortic valve implantation. Am J Cardiol. 2015;115:234-42.

22. Capodanno D, Barbanti M, Tamburino C, D’Errigo P, Ranucci M, Santoro G, Santini F, Onorati F, Grossi C, Covello RD, Capranzano P, Rosato S, Seccareccia F; OBSERVANT Research Group. A simple risk tool (the OBSERVANT score) for prediction of 30-day mortality after transcatheter aortic valve replacement. $\mathrm{Am}$ J Cardiol. 2014;113:1851-8.

23. Seiffert M, Sinning JM, Meyer A, Wilde S, Conradi L, VasaNicotera M, Ghanem A, Kempfert J, Hammerstingl C, Ojeda FM, Kim WK, Koschyk DH, Schirmer J, Baldus S, Grube E, Möllmann H, Reichenspurner H, Nickenig G, Blankenberg S, Diemert P, Treede H, Walther T, Werner N, Schnabel RB. Development of a risk score for outcome after transcatheter aortic valve implantation. Clin Res Cardiol. 2014;103:631-40.

24. Iung B, Laouénan C, Himbert D, Eltchaninoff H, Chevreul K, Donzeau-Gouge P, Fajadet J, Leprince P, Leguerrier A, Lièvre M, Prat A, Teiger E, Laskar M, Vahanian A, Gilard M; FRANCE 2 Investigators. Predictive factors of early mortality after transcatheter aortic valve implantation: Individual risk assessment using a simple score. Heart. 2014;100:1016-23.

25. Beckmann A, Hamm C, Figulla HR, Cremer J, Kuck KH, Lange R, Zahn R, Sack S, Schuler GC, Walther T, Beyersdorf F, Böhm M, Heusch G, Funkat AK, Meinertz T, Neumann T, Papoutsis K, Schneider S, Welz A, Mohr FW; GARY Executive Board. The German Aortic Valve Registry (GARY): a nationwide registry for patients undergoing invasive therapy for severe aortic valve stenosis. Thorac Cardiovasc Surg. 2012;60: 319-25.

26. Carroll JD, Edwards FH, Marinac-Dabic D, Brindis RG, Grover FL, Peterson ED, Tuzcu EM, Shahian DM, Rumsfeld JS, Shewan CM, Hewitt K, Holmes DR Jr, Mack MJ. The STS-ACC transcatheter valve therapy national registry: a new partnership and infrastructure for the introduction and surveillance of medical devices and therapies. J Am Coll Cardiol. 2013;62:1026-34.

27. Cook NR. Use and misuse of the receiver operating characteristic curve in risk prediction. Circulation. 2007;115:928-35. 